\title{
MeCCSA Postgraduate Network 2019 Conference Special Issue: Media Evolution
}

\author{
KATE STUART, Bangor University \\ EOIN MURRAY, Bangor University \\ ISABEL LINTON, Bangor University \\ JORDAN GLENDENNING, Bangor University \\ Guest Editors
}

'Delivery technologies become obsolete and get replaced; media, on the other hand, evolve'. - (Jenkins, 2006, 13)

As technology continues to evolve, so too does media and our interactions with it. For creators, this may manifest in experiments with form, or an ability to adapt to suit a changing medium, while researchers may need to develop new skills and ways of understanding a phenomenon. Regardless of the creative developments chosen or methodologies applied, the continual evolution of media is a challenge new researchers meet in many innovative ways.

The theme of this edition of Networking Knowledge was drawn from the 2019 MeCCSA PGN conference held at Bangor University, Wales, UK. The attending scholars came from all areas of the discipline to discuss the evolution of media. Our opening keynote, Dr Melissa Kagen, discussed a number of case studies, such as Smuggle Truck (rebranded to the more acceptable Snuggle Truck) and Bury Me My Love, as an exploration of borders and the ways that users can evolve their gameplay as a form of protest. Later, Dr Lukasz Szulc expanded on his experiences of finding participants to engage in his study researching LGBTQ+ Polish citizens living in the UK, specifically gay men. Szulc discussed not only the methods he took to find participants but also the potentially ethical issues faced when working with minority participants. Some conference participants narrowed their focus to look at specific creators or creations, such as Arron Santry's examination of Sadie Benning's A Place Colled Lovely1) and the impact uploading their work to YouTube had on the piece itself. Others looked to their own practice, in considering the ethical and cultural implications of changing technology, the disruption in their fields of study, or the evolution of the researcher, as in Xin Cui's ethnographic exploration into film tourism. We were also lucky to welcome both Dr Kaitlynn Mendes and Dr Eben Muse, who helped us in our own evolution by talking about academic job hunting and academic publishing, thus developing our skills and understanding in ways that will help our progression as researchers. Our final keynote, Dr Crystal Abidin, 
drew all of these perspectives together - from the evolution of the platform to the evolution of the researcher - to discuss her research on the social media platform Tumblr. This special edition of Networking Knowledge contains a snapshot of the knowledge exchanged at the Bangor conference, illustrating the varieties in media evolution, from the evolution of a researcher and the participants they observe, to the evolution of a platform like the photo sharing social network, Instagram.

The first paper in this special edition, "From home to the film location site, from a film audience to a film tourist", examines the evolution from film audience to film tourist. Xin Cui's ethnographic study builds upon their experience as both a researcher and participant visiting the Hengdian World Studios. Utilising this combination of observation and personal experience through the journey from home to the film studio, Cui discusses the strength of incorporating both ethnographic and autoethnographic methods in the study of film tourism as enabling a fuller immersion in the research and thus a greater understanding of the data collected. The article discusses the motivations and emotions associated with such a journey, with particular attention paid to the issue of authenticity within film tourism, mapping the participant's evolution from someone who only watches a film to someone who has been fully immersed in it.

Aaron Santry's paper, “'A Place Called Lovely1)': the HD Afterlife of Low-Res Feminist Video Art", draws the focus away from the researcher and instead examines a specific case study, exploring how Sadie Benning's A Place Colled Lovely1), which was originally recorded on an analogue device (a Fisher Price PXL-2000 camcorder), was altered by the process of being digitised and uploaded to sites such as YouTube and Ubuweb. The article evokes the evolution of enhancement, experience and the recipient. The change in the artefact due to its relocation online and the forced enhancement that resulted from this causes, in the author's own words, 'the sacrifice of sensorial quality for the sake of accessibility' (Santry, p.3). However, this change in platform does lead to something known as Haptic Visuality. The enhanced images forced upon the piece by YouTube show additional details the original recording device was unable to display in its primary form. These additional elements serve to embody the haptic, merging 'feminist materiality and strategies of embodied subjectification with an aesthetic and social critique of the conditions of image marginalisation', specifically within digital works. The overall piece provides insight into how evolving technology can serve to marginalise certain creative works, transforming a work's original queer, counter-hegemonic resistance in the process of hosting it in an accessible location.

Those who attended the Bangor conference demonstrated their ability to examine their specific fields and note how they had been affected by evolution in media, with the three keynote speakers being no exception. In March 2020, two members of the Bangor committee were able to speak on this further in an interview with Dr Crystal Abidin, where she reflected on her own evolution as a researcher, both personal and in practice, and provided insight into how current postgrads and ECRs may move forward. Drawing on her own experiences as a researcher in the Global South, Dr Abidin provides insight into how we, as researchers, can grow and learn from the subjects we explore and the people we work with; whether this is in 
finding ways to support our fellow academics or in understanding when we need to take a step back from our research. As her final point suggests, media is ever-changing and as such, can evoke a sense of loss as everything is constantly updated and disrupted. Researching media allows us to capture these fleeting moments, to preserve and build understanding, and in doing so, bring meaning to the constant evolution.

And finally, this edition of Networking Knowledge also contains a review of Instagram: Visual Social Media Cultures (Leaver, Highfield, and Abidin 2020). This book discusses Instagram, including how the platform has evolved based on both its users and its competition. The review provides an overview of the book, and its relevance to the evolution of media. In particular, the review highlights the way that the book itself has evolved further than many other academic texts through the addition of a dedicated Instagram account @ polityinstabook, which allows the authors to expand the content of the book, continuing their conversation beyond the written page.

In conclusion, the Bangor conference served to stimulate discussion on the evolution of media from several areas of the discipline. Not only from the evolution of audience \& recipient and enhancement $\&$ experience but also the evolution of academics themselves, studying these areas in new and innovative ways to constantly add to the discourse around media. As a crucial element of society, media will continue to evolve and change in ways that cannot be predicted, and promising new researchers will remain at the forefront of the subject area to provide this valuable and necessary insight. Everything from our perspective of borders, the ways in which we research, social media platforms, data-driven journalism, lowres art, big-data, feminism, news discourse, and many other areas remain crucial aspects of society for new researchers to tackle as media evolves.

The Bangor MeCCSA Team would like to thank MeCCSA PGN for giving us the opportunity to host this wonderful event, Bangor University for access to its facilities, and Dr Melissa Kagen, Dr Lukasz Szulc, Dr Crystal Abidin, Dr Eben Muse, and Dr Kaitlynn Mendes for their keynote speeches and workshops that stimulated much of the discussion between attendees, and ultimately added great value to the conference.

\section{References}

Jenkins, H., 2006. Convergence culture. New York: New York Univ. Press.

\section{Biographies}

Eoin, Kate, Isabel, and Jordan are $\mathrm{PhD}$ researchers from Bangor University who formed the committee for the MeCCSA PGN Conference 2019. As a team, we research various areas in media: utopic manifestation in games, authorship and book culture, creating installations for transmedia texts, and how the web affects the writing of transmedia texts, respectively. 